\title{
Fault Analysis of Marine Electric Hydraulic Grab Based on Fault Tree Analysis
}

\author{
Baocheng $\mathrm{Lu}^{1, \mathrm{a}}$, Jiasheng $\mathrm{Li}^{2, \mathrm{~b}}$ \\ 12 Binzhou Polytechnic, Binzhou 256600, China \\ a 176816963@qq.com, ${ }^{\mathrm{b}} 306194187 @ q q . c o m$
}

\section{Keywords: Fault tree analysis, Grab, Troubleshooting}

\begin{abstract}
Analysis of the electro hydraulic grab's not tightly closed fault were conducted by using fault tree, through analyzing of the working principle, establishing the fault tree, gradual layered investigation, so as to quickly find the source of the fault and repair the grab. Practices have proved that the use of fault tree analysis method can help operators find fault sources quickly, improve work efficiency and save working time, and this technology has high application value in practical work.
\end{abstract}

\section{Introduction}

One ship is equipped with German SMAG PEINER MZGL 15,000-6-s-b-power/hydraulic grab, which has been in good condition since its use.However, during the recent period of use, it was discovered that NO. 1 grab appeared to be slowly automatically opening about $20 \mathrm{~mm}$ after the shutdown, it cause the cargo to leak during the capture process.

The fault tree analysis is a failure point event as a top event, which is divided into three layers from the top-level time to experience intermediate events until the basic event. The troubleshooting is based on the structure and function of the device. In this paper, the fault tree theory combined with the actual repair work fully, effective use of all kinds of possible fault causes, build up the fault tree, the operator step by step to find and analyze the final point of failure. The fault tree analysis is used to diagnose the system in a rapid way, identify the weakest link in the system, find the fault source and eliminate the fault.

\section{Working principle}

Analysis according to the specifications and drawings, when the operator push the control handle to the open position, the control of electricity K04 contactor K1 and time relay, and the hydraulic pump is turn, after check RV3 pump, oil pump into the oil discharge line P2, the oil in the high pressure check valves RV2 enter below the cylinder space, depending on the pressure forces the pistons to move up, the upper piston oil return by hydraulic controlled check valve SV1 into the return pipe road P2, grab open, after $11 \mathrm{~s} \mathrm{K04}$ time relay and K1 contactor power outages.

The operator put the control handle in closed position, K2 K03 time relay and contactor electricity, inversion of hydraulic pump, oil after check RV4 into pump, into the oil discharge line $\mathrm{P} 1$, the check valve RV1 into the upper cylinder, relying on pressure to push the piston moves down, the piston hydraulic controlled check valve the oil in the lower back of SV2, filter F into the fuel tank, grab shut down, t after 23 s K03 time relay and K2 contactor power outages.

\section{Fault analysis}

\section{Phenomenon analysis}

With the instructions and field tests, the electrician repeatedly tests the handle and cable to make sure that the switch and the electrical conductivity are in good condition. Open the control box to see the contact with $\mathrm{K} 1$ and $\mathrm{K} 2$, check and test the time relay K03 and K04. The electric test 
motor is in good condition. With the analysis, the fault point should be in the hydraulic system, so we set the hydraulic system failure to the fault tree of the top event.

\section{Fault tree building}

The hydraulic system fault tree has the top event $\mathrm{T}$, the intermediate event $\mathrm{M}$, and the basic event $\mathrm{X}$.

$\mathrm{X} 1, \mathrm{X} 2, \mathrm{X} 3, \mathrm{M} 1, \mathrm{M} 2$ are the cause of the hydraulic system failure. The three basic event operators, X1 hydraulic oil, X2 hydraulic pump failure and X3 hydraulic oil, can be found during operation. By X4, X5, X6 among three events caused by oil cylinder fault M1 and by X7, by 8, X9 among three events caused by the control block fault M2 after the need to use special measuring tool to measure to determine the fault location (See Fig.1).

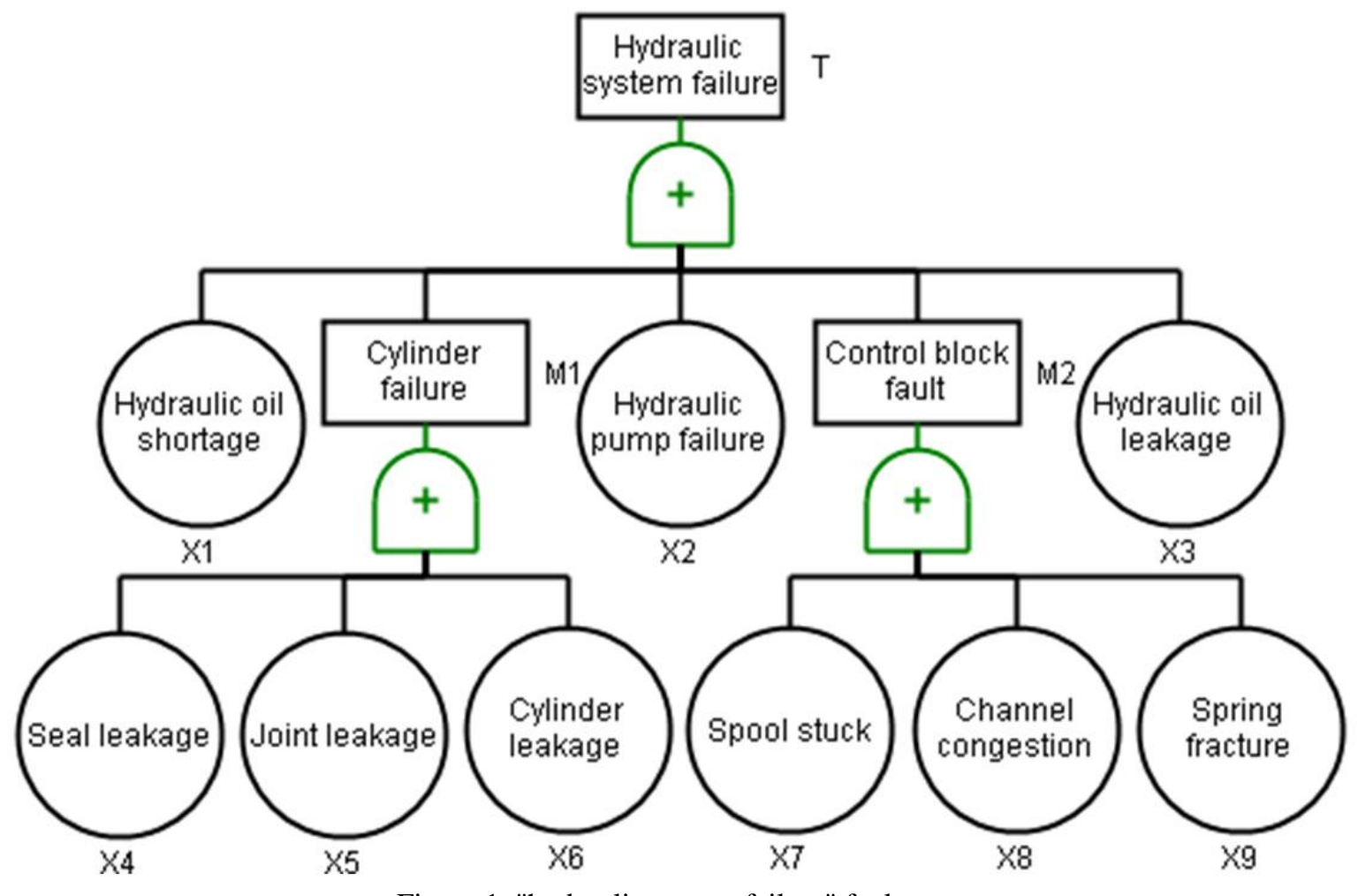

Figure 1 "hydraulic system failure" fault tree

\section{Troubleshooting}

In case of failure, we use the following method, first of all, according to the fault tree, the fault point should be in the oil cylinder fault M1, the control block failure M2. Then we took the elimination method to find the point where we used a special measuring tool to measure the corresponding pressure and the instruction to find the point of failure.

\section{Determine whether the control block is a failure point}

On test control block "closed" and "open" pressure: with two special closed joint closed control block to open and close the hydraulic oil cylinder tubing, respectively in the closed pressure test point MA and MB connect pressure gauge, open the pressure test points are closed and open operation.

The test results were: "MA pressure was 250bar at the time of closing, zero for MB, and over time the pressure of MA began to decline, and the four minutes dropped to 180bar, 6 minutes $160 \mathrm{bar}, 8$ minutes $140 \mathrm{bar}, 10$ minutes, 120 bar. At the time of opening, the pressure of MA and MB was $160 \mathrm{bar}, 4$ minutes to $130 \mathrm{bar}$, and 8 minutes for $120 \mathrm{bar}$. we can think that the control block is normal. 


\section{Determine whether the cylinder is a failure point}

Detection of two cylinders "off" and "open" pressure, loosen the two oil cylinder pressure detection on joint, fitted with special hose and detection of oil (0-400 bar), the closed and open operation.

The test results were: 230 bar when closed, after 8 minutes the pressure dropped to zero, and the grab opened about $80 \mathrm{~mm}$. The pressure was $140 \mathrm{bar}$ at open, and then down to 120bar in five minutes. It is possible to judge the leakage within the hydraulic system.

Detection closed cable joint end hydraulic cylinder "off" pressure: tubing reset, with two special closed joint closed to filter the hydraulic oil cylinder tubing, hydraulic cylinder on the cable joint end on testing pressure gauge, closing operation: closing pressure of 260 bar, after 5 minutes fell to 240 bar, grab is not open, show that the oil cylinder no problem.

Detection closing filter side hydraulic cylinder "off" pressure: closed to the hydraulic oil cylinder tubing, cable joint end on the filter end put test pressure gauge hydraulic oil cylinder and closing operation: closing pressure of 230 bar, to zero after 5 minutes, open the grab bucket. Show that the cylinder is leaking.

In summary, we judge that the bucket is leaking X6 near the filter end cylinder.

\section{Fault analysis and treatment}

\section{Fault analysis}

Through comprehensive analysis, the cause of the leakage in the oil cylinder is the damage of the piston sealing washer or the inner wall of the cylinder. Causes of damage, of which the quality of hydraulic oil is good or bad. If the hydraulic oil contains metal particles and other rigid impurities, will soon cause sealing gasket damage and oil cylinder wall forming abrasive wear and cause oil leakage. The general hydraulic equipment shall be replaced with hydraulic oil and oil filter cartridge after the first 500 hours of operation, and shall be replaced every 1000 hours.

It has been verified that the hydraulic oil and filter core have not been replaced since the grab has been put into use. Check that the oil is dirty and black, and the oil filter is dirty and black.

\section{Oil change treatment}

Keep the grab on the shelf (safety while on the voyage, and all the oil in the hydraulic cylinder back into the tank, the oil is more complete). Loosen the oil gauge. Place a suitable funnel at the bottom of the tank and place a suitable funnel. Unscrew and clean the plug; Release oil from the tank (be careful to avoid spilling over into the sea); Clean the tank with clean oil; Replace the filter core; Rescrew the loose plug; Filling the tank with oil (through the filter); Check the oil level, keep in between scale of oil dipstick, namely from the fuel tank on a plane, about 60-100 - mm (when closed grab the piston rod to recover oil cylinder, a total of about 300 1), too much will cause oil pressure on the high side, too little will cause overheating and damage of oil pump in the hydraulic system. If you don't control the oil well, you can remove some oil from the filter hole.

The replacement of hydraulic oil should be determined based on the results of the regular sampling test, given the difficulty of keeping track of the working hours. So that you can avoid premature caused by abnormal extreme working conditions of hydraulic oil spoiled or damaged equipment aging, and can avoid early replacement of good quality hydraulic oil and cause unnecessary waste.

\section{Replacement of spare parts}

The disassembly of the oil cylinder: the clamshell of the open state shall be put down, and the clamshell should be removed from the bottom of the cylinder to be removed without the obstruction of the beam. Loosen the lock bolt (double head bolt) of the piston rod. Use a special wrench (136 $\mathrm{mm}$ wide) to loosen the fixed nut. It will lift the hydraulic cylinder vertically. Start the hydraulic system, "click" close grab, make the piston rod contract in the hydraulic cylinder, and pull out the cone-shaped set. One thousand the piston rod can't quit, can be heated liang cone fixed set of 
peripheral, a closed grab point move at the same time, the piston rod and the fixed set of connection release after piston rod retracted, loose unloading 12 piston rod guide cloth fastening bolt, discharge guidance department and piston rod, check that the piston rod, piston seal components and hydraulic oil cylinder wall; Remove the connection hose from the hydraulic cylinder and suspend the hydraulic cylinder on a suitable hanger. After releasing the pin locking device on the lower beam, lift the oil cylinder gently, so that the hydraulic cylinder fixed pin can be removed from the side, and the oil cylinder sealing ring is replaced.

\section{Concluding remarks}

After replacing spare parts, the grab is running normally. The bucket is stored on the shelf, and when the ship sails in the sea, the bucket parts are easily eroded by the wind and waves, so it must be well maintained. All the lubrication points (marked in red) will be lubricated once a week to keep alive. The cable terminals are pressed to prevent water from being flooded. In addition, there is a protective shield outside the motor and the control block, but there is a loop of heat sink around it, and the parts are also eroded by the wind and waves. A cylindrical canvas cover $(78 \mathrm{x}$ height in diameter) can be made from the outside of the protective cover. Lift cylinder piston rod telescopic point also can be used as a fold-down dustproof canvas cover, to prevent dust, particles sticking on the piston rod when cargo caused by the wear of the piston rod and seal.

In this paper, the use of fault tree analysis method for system analysis, from the grab closed lax fault phenomena, find out the cause of failure, one by one to list the possible fault source, combining fault phenomenon, hydraulic system principle, the operator test screening step by step, can accurately locate fault source and eliminate, can improve the efficiency of search and troubleshooting.

\section{Reference}

[1] Jian Feng Yang; Ling Ling Chen; Wen Bin Liu. The Failure Cause and Fault Tree Analysis to the Blade of Flue Gas Turbine [J]. Applied Mechanics and Materials. 2016(121)

[2] Ye mao Chen chuanrui Lu yundong Ceng Jiaxiang.Based on the fault tree analysis method, the brake control system of a certain aircraft is found out[J] Engineering.2017

[3] Dang lin, Han liangang, Zhang tuo.Fault diagnosis of a missile borne recorder based on fault tree[J]. industrial control computer.2017

[4] Wang Fei; Shen Guohua; Huang Zhiqiu;Ma Lin;Liu Chang;Li Haifeng;Liao Lili. A method of software security verification combined with linear temporal logic and fault tree [J]. computer science. 2015(12) 